$\xi=\mathrm{\alpha}$

\title{
Optimization of cadmium(II) adsorption onto modified and unmodified lignocellulosics (rice husk and egussi peeling)
}

\author{
Tchuifon Tchuifon Donald Raoul ${ }^{1}$, Nche George Ndifor-Angwafor ${ }^{1}$, Ngakou Sadeu Christian ${ }^{1}$, Kamgaing Théophile ${ }^{1}$, \\ Ngomo Horace Manga ${ }^{2}$, Anagho Solomon Gabche ${ }^{13}$, Ketcha Joseph Mbadcam ${ }^{2}$ \\ ${ }^{1}$ Laboratory of Noxious Chemistry and Environmental Engineering, Department of Chemistry, Faculty of Science, \\ University of Dschang, P.O. Box 67, Dschang, Cameroon \\ ${ }^{2}$ Department of Inorganic Chemistry, Faculty of Science, University of Yaoundé I, P.O.Box 812, Yaoundé-Cameroon \\ ${ }^{3}$ Department of Chemistry, Faculty of Science, University of Bamenda, P.O. Box 39, Bambili, Cameroon \\ *Corresponding author E-mail: solomon.anagho@univ-dschang.org
}

\begin{abstract}
The present study is based on the adsorption of cadmium (II) ions on rice husk and egussi peeling, unmodified and modified with nitric acid in aqueous solution, using batch technique. It was carried out as a function of contact time, dosage, $\mathrm{pH}$ and initial concentration. The equilibrium time was achieved within 25 minutes for unmodified rice husk (Glu NT) and 20 minutes for unmodified egussi peeling (Cuc NT) with an adsorbed quantity of $13.18 \mathrm{mg} / \mathrm{g}$. In the case of modified materials, we obtained 15 minutes for modified rice husk (Glu HNO3) and 10 minutes for modified egussi peeling (Cuc HNO3) with an adsorbed quantity of $18.77 \mathrm{mg} / \mathrm{g}$. The maximum biosorption occurred at $\mathrm{pH} 5.5$ for all biosorbents. The adsorbent mass for maximum adsorption was $0.4 \mathrm{~g}$ giving an adsorption capacity of $62.02 \%$ for unmodified adsorbents. In the case of modified adsorbents, the minimal mass at which maximum adsorption occurred was $0.4 \mathrm{~g}$ giving an adsorption capacity of $98.33 \%$ and $0.6 \mathrm{~g}$ giving an adsorption capacity of $98.33 \%$ for modified rice husk and egussi peeling respectively. The adsorbent/adsorbate equilibrium was well described by the pseudo-second order kinetic model and by Langmuir's and Freundlich adsorption model. This models showed that the adsorption of cadmium (II) is a chemisorption process.
\end{abstract}

Keywords: Biosorption; Cadmium (II) Ions; Lignocellulosic Material; Rice Husk; Egussi Peeling.

\section{Introduction}

The progressive increase of industrial technology results in the continuous increase in environmental pollution. Industries discharge different types of heavy metal wastes into the environment at an unprecedented and at a constant increasing rate to the point where it has become a matter of concern over the last few decades [1]. Heavy metals such as lead, mercury, cadmium, arsenic, chromium and cobalt have been the common pollutants present in environment from various natural and industrial sources. They are found in both surface water and groundwater above the accepted norms [2]. Cadmium is regarded as one of the most toxic elements in the environment because of its high reactivity and its relative solubility in water and in living tissues. The harmful effects of cadmium include a number of acute and chronic disorders, such as renal damage, emphysema, hypertension and testicular atrophy [3]. Hence, it is essential to remove cadmium (II) ions from water and wastewater prior to transport to prevent cycling into the natural environment. The most important technologies employed to remove cadmium include chemical precipitation, electroflotation, ion exchange, reverse osmosis and adsorption onto activated carbon [4]. Adsorption has been developed as an efficient method for the removal of heavy metals from contaminated water. A variety of adsorbents, including clays, zeolites, dried plant parts, agricultural waste biomass, biopolymers, metal oxides, microorganisms, sewage sludge, ash and activated carbon have been used for cadmium removal [5], [6], [7]. Cost is an important parameter for comparing adsorbent materials [8]. Activated carbon is considered to be a highly effective adsorbent for heavy metal removal from wastewater, but it is readily solubilized under extreme $\mathrm{pH}$ conditions and also very costly [9]. Low-cost agricultural waste byproducts, such as sugarcane bagasse, rice husk, sawdust, coconut husk, oil palm shell, and neem bark, have been applied to the removal of heavy metals from wastewater. In this study, rice husk, egussi peeling unmodified and chemically modified by nitric acid are used as adsorbent to evaluate the adsorption efficiency of cadmium (II) ions from aqueous solution. Thus, the effect of contact time, $\mathrm{pH}$ and the adsorbate concentration on the uptake of cadmium (II) ions was thoroughly investigated from a kinetic and equilibrium point of view.

\section{Materials and methods}

\subsection{Preparation of biosorbents}

Rice husk was collected from a pre-consumer agricultural product process industry located at Tonga (West Region) and egussi peeling from Edéa (Littoral Region) both in Cameroon. The collected rice husk and egussi peeling were sun-dried and impurities were removed manually. Each of the materials was washed several times with distilled water for 1 hour under agitation and then fil- 
tered to make it free from colored compounds. The residual material so obtained was dried at $80^{\circ} \mathrm{C}$ in an oven for 24 hours, and then ground and sieved to obtain particles of size less than 250 $\mu \mathrm{m}$.

$10 \mathrm{~g}$ of sieved rice husk was agitated in $100 \mathrm{~mL}$ of $\mathrm{HNO}_{3}(2 \mathrm{M})$ at $200 \mathrm{rpm}$ for 6 hours. The mixture was filtered, and the rice husk was washed with distilled water. After washing, the adsorbent was soaked in $0.1 \mathrm{M} \mathrm{NaOH}$ to neutralize the residual acid on the adsorbent. The mixture was filtered, and washed with distilled water. The rice husk was dried at ambient temperature for 2 days and in an oven at $105^{\circ} \mathrm{C}$ for 24 hours. The biosorbent obtain was stored in plastic bags. Egussi peeling were treated in the same manner as rice husk.

The adsorbent obtained was characterize by Infra-Red Fourier Transform Spectroscopy to identify the functional groups and chemical bonding on the adsorbents. The IR-FT was recorded in the wave number range $4000 \mathrm{~cm}^{-1}-400 \mathrm{~cm}^{-1}$ using a Bruker, Alpha-P Spectrometer using Attenuated Total Reflectance method.

\subsection{Preparation of adsorbate}

The stock solution of cadmium (II) $(500 \mathrm{mg} / \mathrm{L})$ was prepared in distilled water using a known amount of cadmium nitrate salt $(\mathrm{Cd}$ $\left.\left(\mathrm{NO}_{3}\right)_{2}\right)$; thereafter, serial dilution solution were made using stock solution.

\subsection{Batch adsorption experiments}

Adsorption experiments were carried out by mechanical agitation at room temperature. For each, $25 \mathrm{~mL}$ of solution of cadmium (II) ions of known initial concentration $(120 \mathrm{mg} / \mathrm{L})$ was treated with a known weight of different adsorbent. After agitation, the solution was filtered and the filtrate was titrated (using complexometric titration method) to determine the residual concentration. Similar measurements were carried out by varying contact time, $\mathrm{pH}$ and initial concentrations. The percentage removal $(\% \mathrm{R})$ and the amount $\left(\mathrm{Q}_{\mathrm{e}}\right)$ adsorbed were calculated using the following expressions:

$\% R=100 \frac{C_{0}-C_{t}}{C_{0}}$

$\mathrm{Q}_{\mathrm{e}}=\frac{\mathrm{C}_{0}-\mathrm{C}_{\mathrm{e}}}{\mathrm{m}} \mathrm{V}$

$\mathrm{C}_{\mathrm{o}}, \mathrm{C}_{\mathrm{e}}$ and $\mathrm{C}_{\mathrm{t}}$ are the initial concentration, the equilibrium concentration and the concentration at time $t$ of cadmium respectively; $\mathrm{V}$ is the volume of the solution, and $\mathrm{m}$ is the mass of the absorbent.

\subsection{Effect of contact time}

To determine the effect of agitation time on the removal process, $0.1 \mathrm{~g}$ of adsorbent was agitated in $25 \mathrm{~mL}$ solution of cadmium of initial concentration $120 \mathrm{mg} / \mathrm{L}$ at various time intervals. Each time, the solution was rapidly filtered and the residual cadmium (II) concentration determined by titration. The percentage removal $(\% \mathrm{R})$ of heavy metal was calculated using Equation (1).

\subsection{Effect of initial $\mathrm{pH}$}

For each adsorbent, the optimal mass of adsorbent obtained at the end of the preceding study was treated with $25 \mathrm{~mL}$ of aqueous solution of dye $120 \mathrm{mg} / \mathrm{L}$, the $\mathrm{pH}$ range of $3.5 .0-6.02 .6$. Kinetics adsorption studies

The kinetics experiments were conducted using a series of $25 \mathrm{~mL}$ solutions containing known amounts of adsorbent and concentration of cadmium (II) ions. The solutions were vigorously agitated at increasing time intervals. At the end of each experiment, the solution was analysed in order to determine the residual metal ion concentration. A number of kinetics models were used to fit the experimental data. These are:

\subsubsection{The pseudo-second order model}

The pseudo-second order chemisorption kinetic equation (Ho and Mckay) [10]: is expressed as equation 3:

$\frac{d Q_{t}}{d t}=K_{2}\left(Q_{e}-Q_{t}\right)^{2}$

Where $\mathrm{q}_{\mathrm{e}}$ and $\mathrm{q}_{\mathrm{t}}$ are the adsorption capacity at equilibrium and at time $\mathrm{t}$, respectively $(\mathrm{mg} / \mathrm{g})$ and $\mathrm{K}_{2}$ is the rate constant for the pseudo-second order adsorption (g/mg.min). For boundary conditions at $\mathrm{t}=0, \mathrm{Q}_{\mathrm{t}}=0$; and at $\mathrm{t}=\mathrm{t}, \mathrm{Q}_{\mathrm{t}}=\mathrm{Q}_{\mathrm{t}}$, the integrated and rearranged form of equation (4) is:

$\frac{t}{Q_{t}}=\frac{1}{K_{2} Q_{e}{ }^{2}}+\frac{t}{Q_{e}}$

\subsubsection{Intraparticle diffusion model}

The rate of adsorption is known to be controlled by several factors including the following [11]:

1) Diffusion of solute from the solution to the film surrounding the adsorbent particle;

2) Diffusion through the film to the particle surface;

3) Diffusion from the particle surface to the internal sites on the adsorbent particle;

4) Uptake of solute on the solute surface, and this could involve several mechanisms such as physicochemical sorption, ion exchange, complexation or precipitation.

One type of equation used to model the intraparticle diffusion was developed using the concept of linear driving force. It is expressed as [12], [13]:

$\mathrm{Q}_{\mathrm{t}}=\mathrm{X}_{\mathrm{i}}+\mathrm{K}^{1} \mathrm{t}^{0.5}$

$\mathrm{X}_{\mathrm{i}}$ is the boundary layer diffusion effect, and it depicts the boundary layer thickness, while $\mathrm{K}^{1}$ is the initial rate of adsorption (mg/g.min), and it is controlled by intra-particle diffusivity.

\subsection{Batch equilibrium experiments}

For each run, the adsorbent was mixed with $25 \mathrm{~mL}$ solution of at different initial concentrations from $25-200 \mathrm{mg} / \mathrm{L}$. The suspension was stirred for 40 minutes with modified and unmodified rice husk and egussi peeling. The amount of cadmium ion adsorbed at equilibrium, $\mathrm{Q}_{\mathrm{e}}(\mathrm{mg} / \mathrm{g})$ was calculated using equation (2). Equilibrium data were then fitted by using Langmuir, Freundlich and Temkin isotherms.

\subsubsection{The langmuir isotherm}

The Langmuir adsorption isotherm is uses the equilibrium of adsorption of solutes from solutions. It is expressed as [14]:

$\mathrm{Q}_{\mathrm{e}}=\mathrm{Q}_{\mathrm{m}} \frac{\mathrm{K}_{\mathrm{L}} \mathrm{C}_{\mathrm{e}}}{1+\mathrm{K}_{\mathrm{L}} \mathrm{C}_{\mathrm{e}}}$

Where, $\mathrm{Q}_{\mathrm{e}}(\mathrm{mg} / \mathrm{g})$ is the adsorption capacity at the equilibrium solute concentration, $\mathrm{C}_{\mathrm{e}}(\mathrm{mg} / \mathrm{L})$ is the equilibrium concentration of adsorbate in solution, while $\mathrm{Q}_{\mathrm{m}}(\mathrm{mg} / \mathrm{g})$ is the maximum adsorption capacity corresponding to complete monolayer coverage. $\mathrm{K}_{\mathrm{L}}$ $(\mathrm{L} / \mathrm{mg})$ is the Langmuir constant and it is related to the energy of adsorption. Equation (6) can be rearranged in the linear form:

$\frac{1}{Q_{e}}=\frac{1}{Q_{m} K C_{e}}+\frac{1}{Q_{m}}$

The factor of separation of Langmuir, $\mathrm{R}_{\mathrm{L}}$, which is an essential factor characteristic of this isotherm is calculated by using the relation [15]: 


$$
\mathrm{R}_{\mathrm{L}}=\frac{1}{1+\mathrm{KC}_{0}}
$$

Where $\mathrm{C}_{0}$ is the higher initial concentration of methyl orange, while $\mathrm{K}_{\mathrm{L}}$ and $\mathrm{Q}_{\mathrm{m}}$ are the Langmuir constant and the maximum adsorption capacity respectively.

\subsubsection{The freundlich isotherm}

The Freundlich isotherm is based on adsorption on a heterogeneous surface, and it is expressed as [16]

$$
\mathrm{Q}_{\mathrm{e}}=\mathrm{FC}_{\mathrm{e}}{ }^{1 / \mathrm{n}}
$$

Where $\mathrm{Q}_{\mathrm{e}}(\mathrm{mg} / \mathrm{g})$ is the quantity of solute adsorbed at equilibrium, also called adsorption density; $\mathrm{C}_{\mathrm{e}}$ is the concentration of adsorbate at equilibrium, $\mathrm{F}$ and $\mathrm{n}$ are empirical constants. By taking logarithms on both sides, the equation gives the more convenient linear form:

$$
\ln \mathrm{Q}_{\mathrm{e}}=\ln \mathrm{F}+\frac{1}{\mathrm{n}} \ln \mathrm{C}_{\mathrm{e}}
$$

\subsubsection{The temkin isotherm}

Temkin isotherm model predicts a uniform distribution of binding energies over the population of surface binding adsorption. The linear form of Temkin equation is expressed as [3]:

$\mathrm{Q}_{\mathrm{e}}=\frac{\mathrm{RT}}{\mathrm{b}} \ln (\mathrm{ACe})$

The linear form of this equation is given by:

$\mathrm{Q}_{\mathrm{e}}=\mathrm{B} \ln \mathrm{A}+\mathrm{B} \ln (\mathrm{Ce})$

Where, $\mathrm{B}=\frac{\mathrm{RT}}{\mathrm{b}}$; $\mathrm{T}$ is the absolute temperature in Kelvin; $\mathrm{R}$ is the universal gas constant, $8.314 \mathrm{~J} / \mathrm{mol} \mathrm{K}$ and $\mathrm{B}$ is the Temkin constant related to heat of sorption $(\mathrm{J} / \mathrm{mg})$.

\section{Results and discussion}

\subsection{Adsorbents treatment}

Figure 1 shows the retention of cadmium on raw and processed materials.

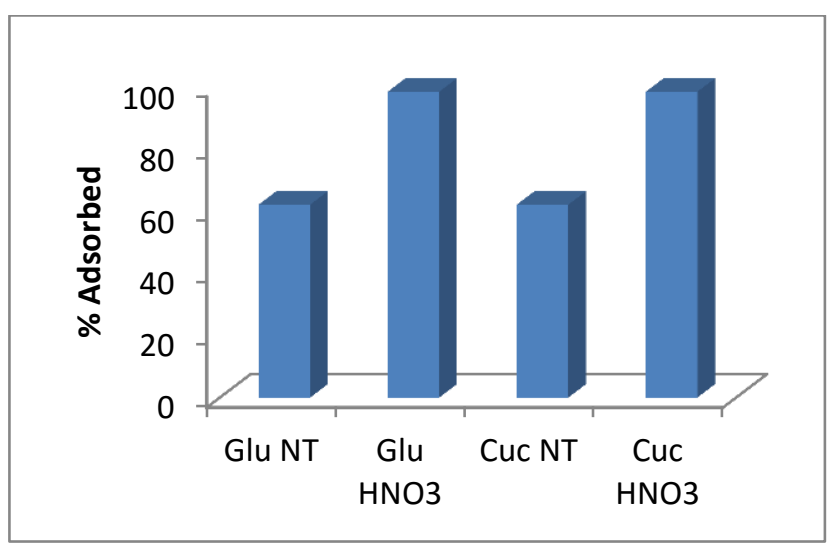

Fig. 1: Uptake of Cadmium (II) Ions onto Modified and Unmodified Rice Husk and Egussi Peeling.

The higher percentage obtained can be explained by the fact that acid treatment of lignocellulosic materials is an irreversible process that leads to a change in supramolecular structure and its morphology, facilitating the solubility of hemicelluloses as well as removing such extractibles [17]. This process permits the formation of different types of bonds with heteroatoms such as oxy- gen and nitrogen $\left(-\mathrm{OH},-\mathrm{NO}_{2},-\mathrm{NO}_{3}\right)$ available to react with the metal ions [8]. According to this, the solubilizations of hemicelluloses are going to increase the adsorption capacity of our biosorbents.

It is also important to note that, the amount of $\mathrm{NaOH}$ used to neutralize the remaining acid after the acid treatment is able to increase the amount of hydroxyl groups by changing the structure of cellulose [3].

\subsection{FTIR spectra}

The FT-IR spectroscopy was used to determine the various functional groups present in adsorbent materials. The spectrums obtained are shown below.
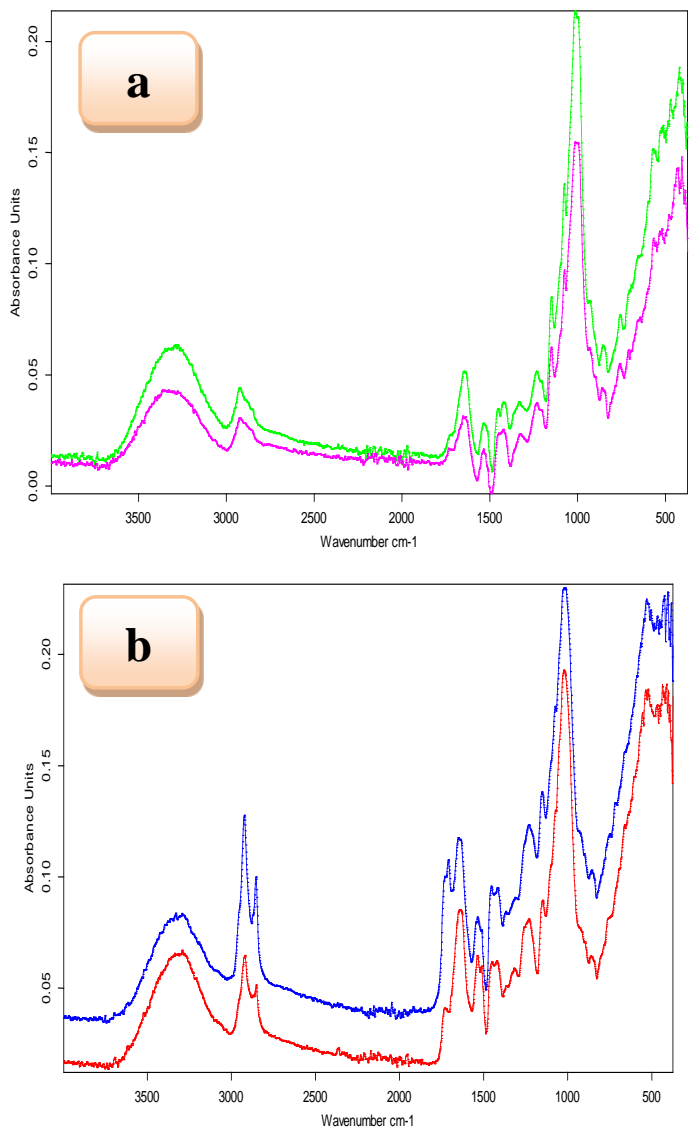

Fig. 2: (A) IR Spectra of Rice Husk (Unmodified (Green) and Modified (Pink)) and (B) IR Spectra of Egussi Peeling (Unmodified (Blue) and Modified (Red)).

Comparing the adsorption peaks with those obtained for lignocellulosic materials by Fazal \& Rafique (2012) [18] and of omaja \& Yuh-Shan (2006) [19] the following analyses can be obtained: $3300 \mathrm{~cm}^{-1}$ : $-\mathrm{OH}$ vibration of chelate and phenolic groups in the main constituents of lignocellulosic materials; $2860-2900 \mathrm{~cm}^{-1}$ : $\mathrm{CH}_{3}$, - $\mathrm{CH}$ and $-\mathrm{CH} 2$ vibration in cellulose, hemicelluloses and lignin; $1650-1740 \mathrm{~cm}^{-1}$ : $-\mathrm{C}=\mathrm{O}$ vibration; $1260 \mathrm{~cm}^{-1}$ : $-\mathrm{C}-\mathrm{O}$ vibration in carboxylic acids; $1050-1300 \mathrm{~cm}^{-1}$ : $-\mathrm{C}-\mathrm{O}$ vibration in lactones.

Figure 2 shows that, all the spectra have the same peaks. This is proof that both biosorbents have identical functional groups on their surfaces. The low intensity of peaks for modified materials indicates the removal of hemicellulose [3]

\subsection{Effect of $\mathrm{pH}$}

The initial $\mathrm{pH}$ is reported to be one of the most critical parameters in the adsorption process which affects surface charge of the adsorbent material and the degree of ionization and specification of adsorbate [20]. Researchers have shown that different metals re- 
quire different $\mathrm{pH}$ levels for their removal using specific adsorbents. The $\mathrm{pH}$ determines the net charge on the biomass and this invariably determines whether the metal ions can bind or not [21].
Figure 3 shows the result of the effect of $\mathrm{pH}$ onto the adsorption of cadmium (II) ions.

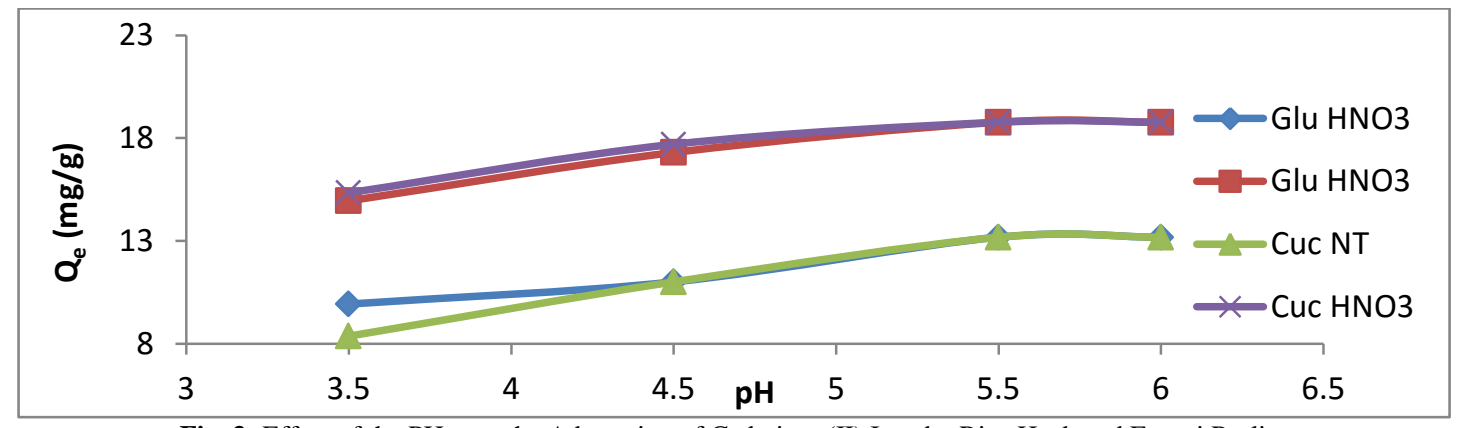

Fig. 3: Effect of the PH onto the Adsorption of Cadmium (II) Ions by Rice Husk and Egussi Peeling

Figure 3 shows that adsorption is maximal at the $\mathrm{pH} 5.5$ with $13.18 \mathrm{mg} / \mathrm{g}$ and $18.77 \mathrm{mg} / \mathrm{g}$ as quantities adsorbed respectively for unmodified and the modified biosorbents.

At $\mathrm{pH}$ lower than 5.5, the small percentage of the cadmium (II) ions adsorbed can be explained by the electrostatic repulsion between the hydronium ions and the cadmium (II) ions at the level of the adsorption sites [18]. This result can also be explained by the studies made by Sousa et al., (2012) [3] who show that $99 \%$ of cadmium ions in solution are positively charge $(2+)$ in the $\mathrm{pH}$ zone $4.5-5.5$ and beyond this value, precipitation begins. The FT-IR spectra shows that the biosorbents used contain ionizable groups such as carboxyls and alcohols which are negatively charge at $\mathrm{pH}$ higher than 4 and therefore are able to complex with metal ions in aqueous solution.

\subsection{Effect of agitation time}

Figure 4 shows the result of the effect of agitation time onto the adsorption of cadmium (II) ions.

Figure 4 shows a fast adsorption of cadmium (II) ions during the first 15 minutes. This quick adsorption reaches equilibrium after 20 minutes for both modified biosorbents $\left(\mathrm{Glu} \mathrm{HNO}_{3}\right.$ and $\mathrm{Cuc}$ $\mathrm{HNO}_{3}$ ), 20 minutes for unmodified egussi peeling (Cuc NT) and 25 minutes for unmodified rice husk (Glu NT). It should be noted from the above result that adsorption proceeded in two phases for both biosorbents.

The fast phase which lasted for 15 minutes, with a maximum quantity of adsorption of $12.09 \mathrm{mg} / \mathrm{g}$ for unmodified biosorbents and $17.7 \mathrm{mg} / \mathrm{g}$, can be explained by the availability of all the sites of adsorption that are present on the surface of the biosorbents [22]. The second phase progressed slowly until equilibrium. This second phase can be explained by the fact that when the cadmium
(II) ions are fixed at surface, they block the pores and slow down the speed of adsorption. The above trends were also obtained by some authors who worked on the adsorption of cadmium (II) ions using lignocellulosic materials other than ours [23], [24], [25]

\subsection{Effect of initial concentration}

The initial concentration of metal ions in solution determines the amount of metal ions biosorbed by the biomass in the presence of available active sites. Figure 5 shows the result of the effect of initial concentration on the adsorption of cadmium (II) ions.

In figure 5 we observe the increasing of the quantity adsorb with the increasing of cadmium (II) ions in solution. This level represents the stage occurring during the adsorption of cadmium (II) ions. These include higher adsorbent-adsorbate interactions considered as the formation of chemical bonds. We can thus say that for both biosorbents, chemisorption occurred. The quantity of cadmium (II) ions adsorbed increases with the amount of cadmium (II) ions in solution.

\subsection{Adsorption isotherm studies}

The effect of initial concentration was studied and the results used to isotherm studies. The adsorption isotherms relate the amount of solute adsorbed at equilibrium $\mathrm{Q}_{\mathrm{e}}(\mathrm{mg} / \mathrm{g})$ to cadmium (II) ions concentration at equilibrium, $\mathrm{C}_{\mathrm{e}}(\mathrm{mg} / \mathrm{L})$ and the plots are given in figure6. The adsorption isotherm parameters are shown in table 1. The correlation coefficients of adsorption are quite high for all the models.

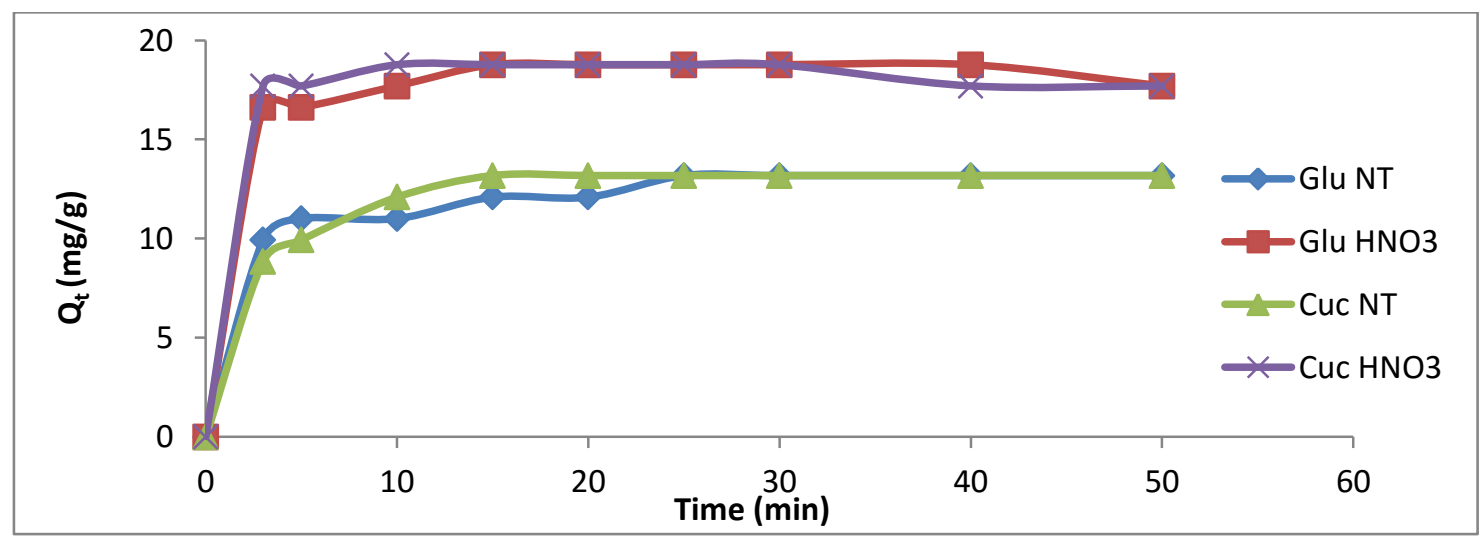

Fig. 4: Effect of Contact Time onto the Adsorption of Cadmium (II) Ions by Modified and Unmodified Rice Husk and Egussi Peeling. 


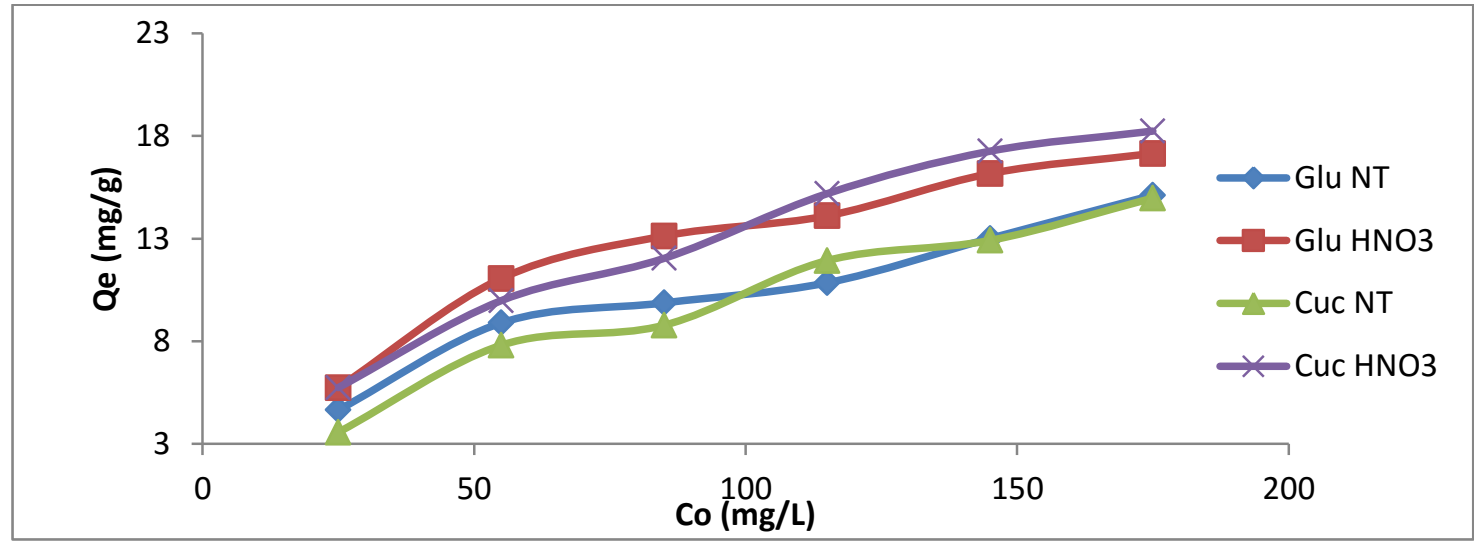

Fig. 5: Effect of Initial Concentration of Cadmium (II) Ions on Adsorption of Modified and Unmodified Rice Husk and Egussi Peeling.
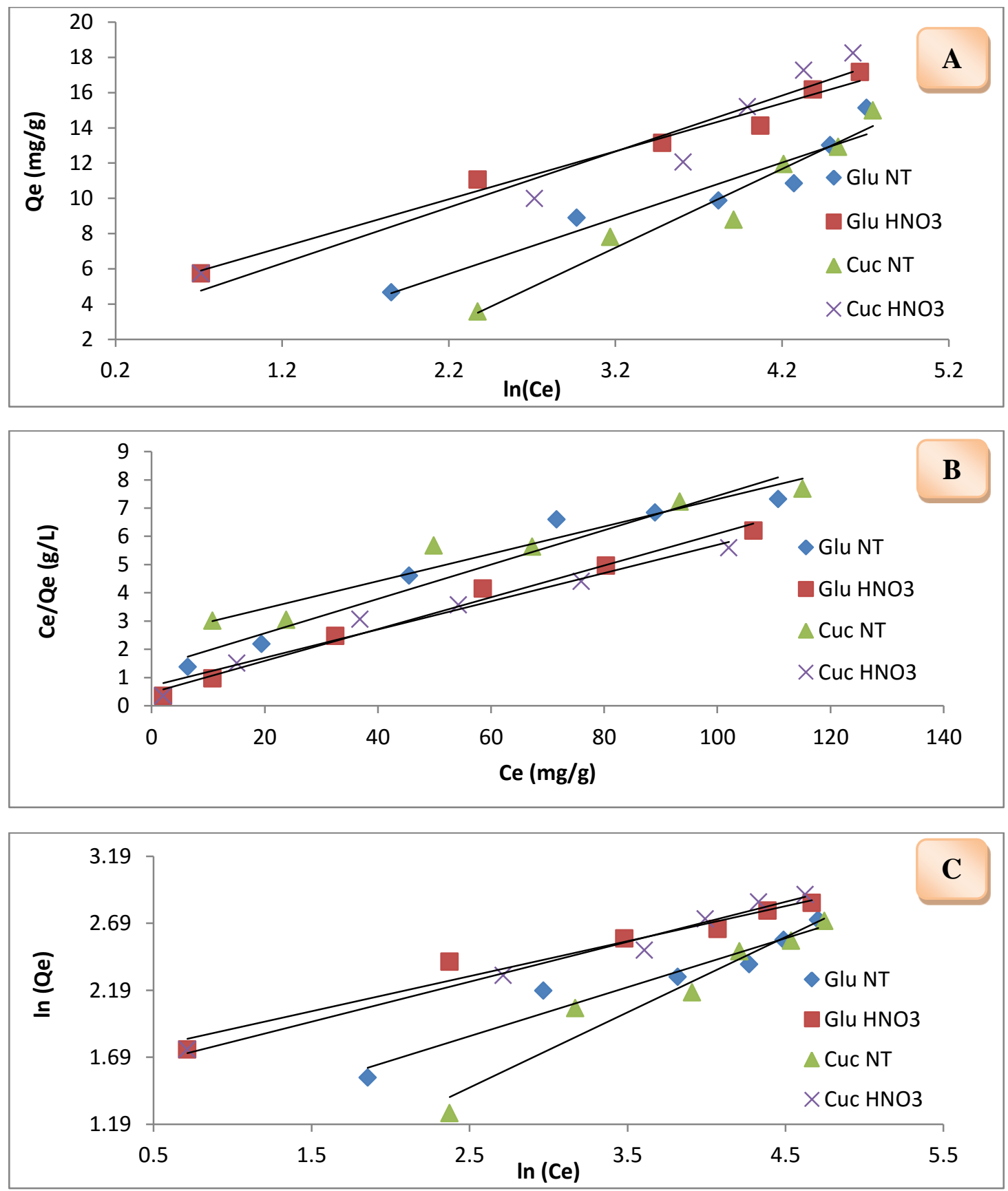

Fig. 6: Isotherm Models: (A) Temkin, (B) Langmuir And (C) Freundlich

Langmuir model have correlation coefficient above 0.94. The values of $1 / n$ of the Freundlich model are lower than 1 and the constants of the Temkin model are lower than 5. These observa- tions permit us to say that, the process of fixation of the ions on the adsorbent is chemisorption [3], [22], [23], [25]. 
Table 1: Langmuir, Freundlich and Temkin Constants and Adsorption Parameters.

\begin{tabular}{llllllllll}
\hline Models & \multicolumn{3}{c}{ Langmuir } & \multicolumn{3}{c}{ Freundlich } & \multicolumn{3}{c}{ Temkin } \\
\hline $\begin{array}{l}\text { Para- } \\
\text { meters }\end{array}$ & $\mathrm{K}_{\mathrm{L}}$ & $\begin{array}{l}\text { Qm } \\
(\mathrm{mg}\end{array}$ & $\mathrm{R}^{2}$ & $\mathrm{~K}_{\mathrm{F}}$ & $1 / \mathrm{n}$ & $\mathrm{R}^{2}$ & $\begin{array}{l}\mathrm{A} \\
(\mathrm{L} /\end{array}$ & $\begin{array}{l}\mathrm{B} \\
(\mathrm{J} / \mathrm{m}\end{array}$ & $\mathrm{R}^{2}$ \\
$\mathrm{Glu}$ & 0.0 & 17.7 & 0.9 & 1.4 & 0.5 & 0.9 & 1.79 & 3.46 & 0.9 \\
$\mathrm{NT}$ & 38 & 6 & 41 & 57 & 05 & 39 & 8 & 1 & 12 \\
$\mathrm{Glu}$ & 0.1 & 17.7 & 0.9 & 5.1 & 0.2 & 0.9 & 4.27 & 2.72 & 0.9 \\
$\mathrm{HNO}_{3}$ & 22 & 9 & 88 & 55 & 61 & 61 & 4 & 3 & 80 \\
$\mathrm{Cuc}$ & 0.0 & 20.7 & 0.9 & 4.5 & 0.2 & 0.9 & 4.88 & 4.46 & 0.9 \\
$\mathrm{NT}$ & 19 & 0 & 42 & 19 & 98 & 45 & 9 & 8 & 53 \\
$\mathrm{Cuc}$ & 0.0 & 20.0 & 0.9 & 1.0 & 0.5 & 0.9 & 2.19 & 3.17 & 0.9 \\
$\mathrm{HNO}_{3}$ & 72 & 0 & 69 & 64 & 61 & 85 & 7 & 5 & 29 \\
\hline
\end{tabular}

The $\mathrm{R}_{\mathrm{L}}$ values obtained are, 0.131 for unmodified rice husk, 0.231 for unmodified egussi peeling, 0.045 for modified rice husk and 0.073 for modified egussi peeling. These values ranging between 0 and 1 show that the adsorption process is favorable for the adsorbent materials [26], [27]

\subsection{Kinetic studies}

Two kinetic models, the pseudo second order and the intraparticle diffusion models were used to explain the experimental data obtained in this work. The mechanism by which the process of adsorption takes place, such as chemical reaction or diffusion was examined.

- Pseudo second order model

The linear form of the pseudo second order model is given in figure 7. Based on the results, one can say that chemical adsorption dominates the process of adsorption of cadmium ion onto the various modified and unmodified biosorbent.

From table 2, the estimated values of Qe (calculated) are close to the Qe (experimental). All these point to the fact that second order kinetic best explains the observed rate, which means that, the biosorption of the metal ions involves two species - the metal ion and the biomass, and that the biosorption is the rate-limiting step [28]. As seen from table 2, it is evident that the adsorption of cadmium ion onto modified and unmodified biosorbent adequately follows the pseudo second order kinetic model, as the correlation coefficients are higher than 0.99 for both adsorbates. The applicability of the pseudo-second order kinetic model shows that the rate limiting step is chemisorption [29], [30]. According to this model, the interactions can be said to be chemical in nature; thus the bonds between adsorbate and adsorbent are covalent [29].

Table 2: Pseudo-Second Order Constants and Parameters.

\begin{tabular}{|c|c|c|c|c|c|}
\hline Adsorbents & & $\begin{array}{l}\text { Glu } \\
\text { NT }\end{array}$ & $\begin{array}{l}\mathrm{Glu} \\
\mathrm{HNO}_{3}\end{array}$ & $\begin{array}{l}\text { Cuc } \\
\text { NT }\end{array}$ & $\begin{array}{l}\mathrm{Cuc} \\
\mathrm{HNO}_{3}\end{array}$ \\
\hline \multirow{2}{*}{$\begin{array}{l}\text { Pseudo- } \\
\text { second order }\end{array}$} & $\begin{array}{l}\mathrm{K}_{2} \\
(\mathrm{~g} / \mathrm{min} . \mathrm{mg})\end{array}$ & 0,045 & 0,589 & 0,061 & 0,092 \\
\hline & $\begin{array}{l}\mathrm{Q}_{\mathrm{e}}(\mathrm{mg} / \mathrm{g}) \\
\mathrm{R}^{2}\end{array}$ & $\begin{array}{l}13,66 \\
0,996\end{array}$ & $\begin{array}{l}18,25 \\
0,997\end{array}$ & $\begin{array}{l}13,62 \\
0,999\end{array}$ & $\begin{array}{l}17,73 \\
0,998\end{array}$ \\
\hline
\end{tabular}

Weber's intraparticle diffusion model

If intra-particle diffusion is controlled, then $Q_{t}$ versus $t^{1 / 2}$ will be linear and if the plot passes through the origin, then the rate limiting process is due only to intra-particle diffusion. Otherwise, some other mechanism along with intra-particle diffusion must also be involved. Pore-diffusion plots often show several linear segments. It has been proposed that these linear segments represent porediffusion in pores of progressively smaller sizes [3], [30]. When points in a group are identified as belonging to a linear segment, linear regression can then be applied to these points.

The cadmium (II) ions adsorption data were plotted according to equation 5 as shown in figure 9. As seen in figure 8, the points were not linear over the whole time range, implying that more than one process affected the adsorption process and this deviation might be due to the difference in the mass transfer rate in the initial and final stage of adsorption. This indicates that diffusion into one class of pores was not the only rate-limiting mechanism in the adsorption process.

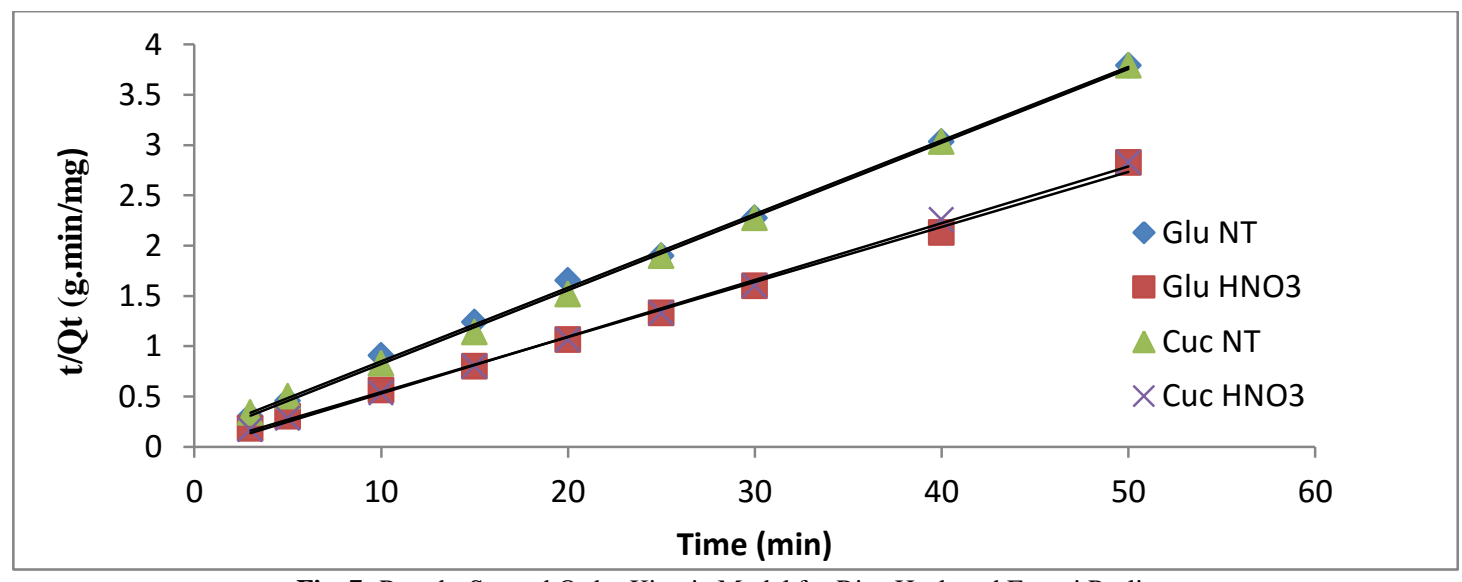

Fig. 7: Pseudo-Second Order Kinetic Model for Rice Husk and Egussi Peeling.

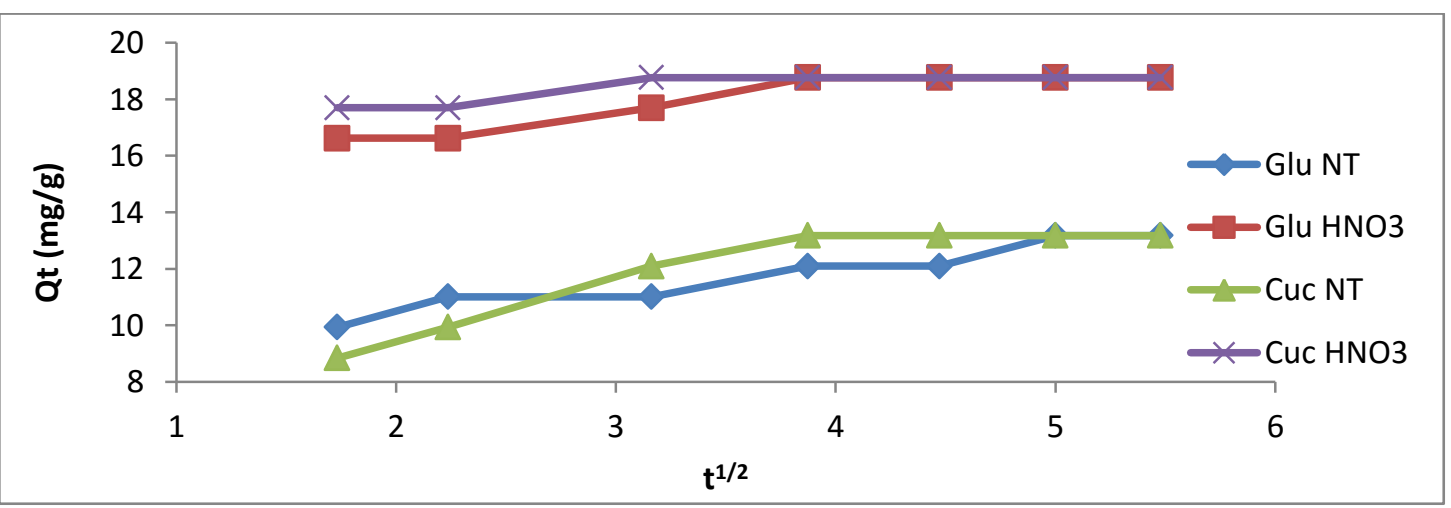

Fig. 8: Weber's Intraparticle Diffusion Kinetic Model for Rice Husk and Egussi Peeling. 


\section{Conclusion}

The batch biosorption studies have shown that the biosorption is $\mathrm{pH}$ dependent and the optimum $\mathrm{pH}$ for the removal of cadmium (II) ions using rice husk and egussi peeling is in range $5.5-6$. Maximum biosorption was obtained within the first $25 \mathrm{~min}$ for unmodified rice husk and $15 \mathrm{~min}$ for the other adsorbents of the process. Kinetic study also showed that the biosorption is well represented by pseudo-second order equation. Both the isotherm models and pseudo-second kinetic models show that the adsorption mechanism of cadmium is chemisorption. The amount of cadmium (II) ions biosorbed increased with increase in initial metal ion concentration. As observed in this study, rice husk and egussi peeling have the capacity to remove cadmium (II) ions from aqueous solutions. Modified and unmodified rice husk and egussi peeling could therefore, be used as potential biosorbent for the removal of cadmium (II) ions from aqueous solutions

\section{Acknowledgements}

Technical assistance rendered by the researchers of LANOCHEE Laboratory of the Department of Chemistry, University of Dschang (Cameroon) is gratefully acknowledged.

\section{References}

[1] Anagho S.G., Ketcha J.M., Tchuifon T. D.R., Ndi J.N., (2013). Kinetic and Equilibrium Studies of the adsorption of Mercury (II) ions from aqueous Solution using Kaolinite and Metakaolinite clays from Southern Cameroon. International Journal of Research in Chemistry and Environment 3, 1-11.

[2] Ketcha J.M..; Anagho S.G.; Ndi J. N., Kammegne M. A., (2011) Kinetic and equilibrium studies of the adsorption of lead (II) ions from aqueous solution onto two Cameroon clays: Kaolinite and smectite. Research Journal of Environmental Chemistry and Ecotoxicology 3, 290-297.

[3] Sousa N.V.O., Tecia V.C., Honorato S.B., Gomes C.L., Baros F.C.F., Araujo-Silvia M.A., Freire P.T. C., Nascimento R.F., (2012). Coconut bagasse treated by thiourea/ammonia solution for cadmium removal: kinetics and adsorption equilibrium. Bioresource Technology 7, 1504-1524.

[4] Tchuifon Tchuifon D.R., Anagho S.G., Njanja E., Ghogomu J.N., Ndifor-Angwafor N. G., Kamgaing T., (2014). Equilibrium and kinetic modelling of methyl orange adsorption from aqueous solution using rice husk and egussi peeling. International Journal of Chemical Sciences 12(3), 741-761.

[5] Essomba J.S., Ndi J.N., Belibi B.P.D., Tagne G.M. Ketcha J.M., (2014). Adsorption of cadmium (II) ions from aqueous solution onto kaolinite and metakaolinite. Pure and Applied Chemical Sciences 2(1), 11 - 30

[6] Abdellah A., Abdelkader I., Mohand S.O., (2007). Hg (II) sorption from aqueous solution by blast -furnace slag. Water Quality Research Journal of Canada 42 (1), 41-45.

[7] Akporhonor E.E., Egwaikhide P.A., (2007). Removal of selected metal ions from aqueous solution by adsorption onto chemically modified maize cobs. Scientific Research and Essay 2(4), 132-134.

[8] Vieira R.S.H.F., Boya V., (2002). Biosorption: a solution to pollution. International Microbiology 3, 17-24.

[9] Ho Y.S., Chiang T.H., Hsueh Y.M., (2005). Removal of basic dye from aqueous solution using tree fern as a biosorbent. Process in Biochemistry 40 ,

$119-124$ http://dx.doi.org/10.1016/j.procbio.2003.11.035.

[10] Tchuifon Tchuifon Donald Raoul, Anagho Solomon Gabche, Nche George Ndifor-Angwafor, Ketcha Joseph Mbadcam., (2015). Adsorption of salicylic and sulfosalicylic acid onto powdered Activated Carbon prepared from Rice and Coffee Husks. Internationa Journal of Current Engineering and Technology 5(3), 1641-1652.

[11] Igwe J.C., Abia, A. (2007). Adsorption kinetics and Intraparticulate Diffusivities for Bioremediation of $\mathrm{Co}$ (II), Fe (II) and $\mathrm{Cu}$ (II) ions from waste water using modified and unmodified maize cob. International Journal of Physics and Science 2, 119-127.

[12] Igwé J.C., Abia, A.A., Ibeh, C.A., (2008). Adsorption kinetic and intraparticule diffusivities of $\mathrm{Hg}$, as and $\mathrm{Pb}$ ions on unmodified and thiolated coconut fiber. International Journal of Environmental Sci- ences and Technology

$5(1)$

$83-92$. http://dx.doi.org/10.1007/BF03326000.

[13] Volesky B., (2003). Sorption and biosorption. BV Sorbex Inc, Monteal-St.Lambert, Quebec, Canada, 315 P.

[14] Kannan N., Sundaram M. M., (2001). Kinetics and mechanism of removal of Methylene blue by adsorption on various carbons - A comparative study. Dyes and Pigments 51, 25-40. http://dx.doi.org/10.1016/S0143-7208(01)00056-0.

[15] Ebner A.D., Ritter J.A. and Novratil, J.D. (2001). Adsorption of Cesium, Strontium and Cobalt ions on magnetite and a magnetitesilica composite. Industrial and Engineering Chemistry Research 40, 1615-1623 http://dx.doi.org/10.1021/ie000695c.

[16] Saifuddin, N.N. and Raziah A.Z., (2007). Removal of heavy metals from industrial effluent using saccharomyces cerevisiae (bakers' yeast) immobilized in chitosan/Lignosulphonate matrix. Journal of Applied Sciences and Research 3 (12), 2091-2099.

[17] Reppelin V., (2006) Optimisation des paramètres durée et temperature d'un traitement thermique du bois. Modification des propriétés d'usage du bois en relation avec les modifications physicochimiques et ultrastructurales occasionnées par le traitement thermique. Thèse de Doctorat, Ecole supérieure des mines de SaintEtienne, Saint-Etienne, France, 225p.

[18] Fazal A., Rafique U. (2012). Mechanistic Understanding of Cadmium Sorption by Sulfonated and Esterified Spent Black Tea. International Journal of Chemistry and Environmental Engineering 3, 230237.

[19] Ofomaja A.E., Yuh-Shan H., (2005). Effect of pH on cadmium biosorption by coconut copra meal. Chemical Engineering Journal 7, $50-57$.

[20] Imamoglu M., Tekir O., (2008). Removal of copper (II) and lead (II) ions from aqueous solutions by adsorption on activated carbon from a new precursor hazelnut husk. Desalination 228, 108-113. http://dx.doi.org/10.1016/j.desal.2007.08.011

[21] Babarind, N.A.A., Babalola, J.O., (2010). The biosorption of Pb (II) from solution by elephant grass (pennisetum purpureum): kinetics, Equilibrium, and thermodynamics studies. Pacific journal of science and technology, 11, 622-629.

[22] Rao K. S., Mohapatra M., Anand S., Venkateswarlu P., (2010). Review on cadmium removal from aqueous solution. International Journal of Engineering Science and Technology 2, 81-103.

[23] Eun, W.S., Rowell R.M. (2005). Cadmium ion sorption onto lignocellulosic biosorbent modified by sulfonation: the origin of sorption improvement. Chemosphere 60, 1054-1061. http://dx.doi.org/10.1016/j.chemosphere.2005.01.017.

[24] Mona E.O., Moustapha, S.M., (2013). Removal of Cd (II) ion from wastewater by adsorption onto treated old newspaper: kinetic modeling and isotherm studies. International Journal of Industrial Chemistry, 4, 1-7.

[25] Vàzquez G.R., Fernàndez-Bea R., Friere M.S., Gonzàlez-Alvarez J., Antorrena, G., (2007). Determination of equilibrum, kinetic and thermodynamic parameters for the adsorption of cadmium (II) onto Castenea sativa shell. Proccedings of European Congress of Chemical Engineering. Copenhagen, 16-20 september 2007, 1-7.

[26] Tchuifon Tchuifon D.Raoul, Anagho S.Gabche, Ketcha J.Mbadcam, Nche G.Ndifor-Angwafor., Ndi J. Nsami, (2014). Kinetics and equilibrium studies of adsorption of phenol in aqueous solution onto activated carbon prepared from rice and coffee husks. International Journal of Engineering and Technical Research 2(10), 166-173.

[27] Dada A.O., Olalekan A.P., Olatunya A.M., Dada O., (2012). Langmuir, Freundlich, Temkin and Dibinin-Raduskevich isotherms studies of equilibrium sorption on $\mathrm{Zn}^{2+}$ unto phosphoric modified rice husk, Journal of Applied Chemistry, 3(1), 38-45

[28] Wallace M.A. (2003). An Evaluation of Copper Biosorption by Brown Seaweed under Optimized Conditions. Environmental Biotechnology $6,174-184$.

[29] Ho Y.S., (2006). Review of second-order models for adsorption systems. Journal of Hazardous Materials, B136, 681-689 http://dx.doi.org/10.1016/j.jhazmat.2005.12.043.

[30] Ho Y.S., McKay G. (1999). Pseudo- second order model for sorption process. Process Biochemistry, 34, 451-465. http://dx.doi.org/10.1016/S0032-9592(98)00112-5. 